\title{
The present state and future direction of primary care: a qualitative study of GPs' views
}

\author{
Helen Lester, Stephen M Campbell and Ruth McDonald
}

\begin{abstract}
Background

Over the past decade there has been a sharp increase in the number of non-profit-sharing salaried doctors employed by practices. This has been accompanied by the introduction of mechanisms to facilitate the entry of other providers into the primary care market.

Aim

To explore the views of GP principals and salaried doctors on current working practices and the future direction of primary care in England.

Design of study

Qualitative study using semi-structured interviews.

Setting

Twenty-two nationally representative practices across

England, between February and August 2007.

Method

Interviews were conducted with 22 principals and seven salaried doctors. A topic guide included questions on motivations for working in primary care, descriptions of working lives, the way in which clinical time was spent, and predictions for future working conditions.

\section{Results}

Significant changes to GP working arrangements were identified, including increasing pursuit of specialist clinical interests by GP principals and increasing employment of salaried GPs. These developments were reported as improving the working lives of principals but also creating a hierarchical structure at practice level that led to resentment among salaried doctors. Many of the salaried GPs felt disenfranchised and disillusioned by the difference in status and autonomy in decision making and the type of work they performed in the practice. Almost all GPs felt uncertain about the future of primary care and were concerned about the potential threat of private providers delivering primary care within the NHS through a largely salaried workforce.

\section{Conclusion}

By failing to recognise the problems of employing an increasingly disenfranchised salaried labour force, GP principals may be undermining the very ethos of general practice they otherwise advocate and recreating smaller versions of the private provider organisations they suggest threaten to corrode NHS primary care.

Keywords

primary care; salaried GP; workforce.
\end{abstract}

\section{INTRODUCTION}

During the past decade, there have been a number of key changes in primary care in England, particularly in terms of workforce and competition. GPs in England are traditionally self-employed contractors, known as principals, who work in collaboration with other GPs and are profit-sharing partners. Recently, there has been a sharp increase in the number of non-profit-sharing salaried doctors employed by practices. Policy makers originally anticipated these posts as a means of improving recruitment and retention of doctors in primary care, and quality of care, particularly in deprived areas. In 2003, there were 1712 salaried GPs in England, rising to 6022 in 2007 , and by a further $10 \%$ in the past year. The number of principals has remained stable over that time period at around $27500 .^{1}$

Salaried GPs can be employed by a practice or primary care organisation, or an alternative provider of medical services (APMS). A salaried GP has a contract of employment with their employer. This can be implied, oral, or written, and the British Medical Association (BMA) has developed a model salaried contract. ${ }^{2}$ However employers are not obliged to employ salaried GPs under model terms and conditions.

A workforce survey in 2005 found that salaried GPs were more likely to be female, work part-time,

H Lester, MD, professor of primary care; SM Campbell, PhD, senior research fellow; $\mathbf{R}$ McDonald, $\mathrm{PhD}$, senior research fellow, National Primary Care Research and Development Centre, University of Manchester, Manchester.

Address for correspondence

Helen Lester, National Primary Care Research and

Development Centre, the University of Manchester, Williamson Building, Oxford Road, Manchester M13 9PL. E-mail: helen.lester@manchester.ac.uk

Submitted: 7 January 2009; Editor's response: 17 March 2009; final acceptance: 29 April 2009.

(C)British Journal of General Practice.

This article was originally online first on 4 Nov 2009. Cite this article as: Br J Gen Pract 2009; 59: 908-915. Advance online publication. DOI: 10.3399/bjgp09X473060. 
and be more geographically mobile than principals. ${ }^{3}$ However, there is little evidence to suggest that they have relieved inequalities in GP distribution. Research prior to 2005 also suggested salaried GPs were less stressed and had similar job satisfaction levels to GP principals, ${ }^{4}$ and were perhaps creating a new type of primary care, based on a stimulating but controlled workload within a democratic working environment. ${ }^{5}$

This decade has also seen the introduction of mechanisms to facilitate the entry of other providers into the primary care market. ${ }^{6}$ Recent contractual reforms in England have ended the GPs' monopoly over the provision of primary care to the NHS, and resulted in an expansion of market forces in primary health care. ${ }^{7}$ These, at times politically contested, changes are part of a broader policy direction in the UK to encourage a market within the NHS with greater managerial control and competition between different types of provider, including larger private companies. $^{8}$ Some of these newer models of providing primary care, such as APMS, rely more heavily on a workforce of salaried GPs to provide face-to-face patient care than traditional practices.

This study aimed to gather in-depth empirical evidence on the views of both salaried GPs and GP principals on current working practices and the future of primary care. This article analyses some of the key contradictions and tensions in what was heard, contextualised by the wider political changes.

\section{METHOD}

\section{Participants and setting}

Face-to-face semi-structured interviews with 22 principals and seven salaried doctors in practices across England were carried out by all of the authors between February and August 2007. The practices were drawn from a nationally representative cohort of practices, ${ }^{9}$ based on number of doctors working in the practice and the socioeconomic deprivation of the locality. Twenty-two practices were located in six geographical areas of England: Avon, Bury/Rochdale, Enfield/Haringey, South Essex, Oldham, and Somerset. Practice size and staff are show in Table 1. Each salaried GP was employed in one of the principals' practices, enabling a comparison of the views of people working together in the same practice.

The topic guide was developed from the interviewers' a priori questions, and issues identified in previous work with the same practices undertaken by the study team. ${ }^{10}$ In particular, interviewers asked about motivations for working in primary care, descriptions of current working lives, the way in which clinical time was spent each day, and predictions of future working conditions.

\section{How this fits in}

There is an increasing number of salaried doctors employed by GP principals in primary care, and the working patterns of doctors within primary care are changing. This study found that, compared to GP principals, some salaried GPs feel disenfranchised and disillusioned by the difference in status and autonomy in decision making, and the type of work they perform. GP principals may be failing to recognise the problems of employing an increasingly disenfranchised salaried labour force, recreating smaller versions of the private provider organisations they suggest threaten to erode NHS primary care.

\section{Data analyses}

Interviews lasted between 40 and 60 minutes. All interviews were digitally recorded and fully transcribed. Data collection and analysis occurred concurrently. Data collection from the GP principals continued until theoretical saturation was reached. All salaried GPs employed by the surgeries were approached for an interview and their responses compared with those of the GP principals. Confidentiality was assured and no doctors' comments were discussed with other participants. Responder validation of transcripts and emerging themes was available to participants

\section{Table 1. Characteristics of participating practices.}

Practice ID Practice summary

\begin{tabular}{|c|c|}
\hline 1. & 2 GPs (1 FTE job-share), 1 part-time PN; 1773 patients \\
\hline 2. & 1 full-time GP, 1 registrar, 1 full-time and 1 part-time PN; 2020 patients \\
\hline 4. & 8 GPs (7.2 FTE), 4 part-time PNs, 2 HCAs; 13200 patients \\
\hline 7. & 1 GP, 1 part-time PN; 2006 patients \\
\hline 8. & 5 GPs (3.2 FTE), 1 full-time and 2 part-time PNs, 1 HCA; 8300 patients \\
\hline 10. & 7 GPs (5.8 FTE), 4 full-time PNs; 10234 patients \\
\hline 15. & 4 full-time GPs, 2 registrars, 4 part-time PNs, $1 \mathrm{HCA} ; 8600$ patients \\
\hline 20. & 2 full-time GPs, 1 full-time PN, 1 HCA; 4555 patients \\
\hline 21. & 8 GPs (7 FTE), 2 registrars, 6 part-time PNs, 2 HCAs; 10900 patients \\
\hline 23. & 9 GPs (8 FTE), 1 registrar, 5 part-time PNs, 1 HCA; 15291 patients \\
\hline 25. & 2 full-time GPs, 2 part-time PNs; 3232 patients \\
\hline 30. & 4 GPs (3.5 FTE), 3 part-time PNs; 6000 patients \\
\hline 32. & 1 GP, 1 part-time PN; 2376 patients \\
\hline 38. & 2 full-time GPs, 1 part-time PN; 3900 patients \\
\hline 39. & 11 GPs (10 FTE), 1 registrar, 5 part-time PNs, 2 HCAs; 18700 patients \\
\hline 41. & 3 full-time GPs, 2 part-time PNs; 6600 patients \\
\hline 47. & 8 GPs (7.5 FTE), 3 part-time PNs; 9100 patients \\
\hline 49. & 8 GPs (6.5 FTE), 1 registrar, 4 PNs ( 3 part-time); 10700 patients \\
\hline 52. & 2 GPs (1.75 FTE), 1 full-time and 1 part-time PN; 3700 patients \\
\hline 54. & 6 GPs (3.2 FTE), 1 registrar, 1 full-time and 1 part-time PN; 7500 patients \\
\hline 55. & 2 full-time GPs, 3 part-time PNs; 2958 patients \\
\hline 58. & 5 GPs (3.2 FTE), 1 full-time and 1 part-time PN; 6327 patients \\
\hline
\end{tabular}

$F T E=$ full-time equivalent. $P N$, practice nurse. $H C A=$ healthcare assistant. 
but none were requested. Each transcript was read by at least two of the research team independently, and a preliminary coding frame constructed. A constant comparative method was used to interpret the data. ${ }^{11}$ Key concepts were identified using an open coding method. Once coding was completed, the codes that had common elements were merged to form categories. All authors were involved in this process, and disagreements were discussed until a consensus was achieved. Disconfirming evidence was actively sought throughout. ${ }^{12}$ Analysis also took into account the salaried or principal status of the participants. All quotations have been chosen on grounds of representativeness.

One of the authors is a GP and two are nonclinical health services researchers. All authors have a research interest in the quality of care within primary care.

\section{RESULTS}

Thirty-one health professionals in 23 nationally representative practices were invited to participate (23 principals and eight salaried doctors). Twentynine of these GPs (94\%) agreed to be interviewed (22 principals, each from a different practice, and seven salaried doctors employed by seven different practices). GP principals were aged between 39 and 64 years, and salaried GPs between 31 and 61 years. Most of the salaried GPs had been in post for approximately 4 years. All except two principals worked full-time and five were female. All except two salaried GPs worked half-time and six were female. Practice size varied from 1773 to 18700 registered patients (mean 7438 patients).

This article reflects the views of GP principals and salaried GPs, particularly in relation to the changes to medical work, the creation of new practice hierarchies, and the future of general practice.

\section{Changes to medical work}

Most principals argued that although elements of traditional primary care work, such as bereavement and postnatal visits, had all but disappeared, the core elements of the primary care consultation had not changed during their working lives. GP principals described the importance of providing longitudinal and interpersonal continuity of care. Salaried GPs shared the enjoyment of being part of a community, and also emphasised the flexibility of working familyfriendly hours. Almost all of the interviewees also described the importance of personal autonomy and independence in their work:

'I like the self-employedness of being in control of your own destiny, so to speak, independence and autonomy is important, your own job in your own way.' (GP principal, practice 41)

'In some, some respects my role hasn't changed and never will do, as far as I can see and not in my lifetime anyway, you know, the person comes in the door, sits down and ask them what's wrong and you try and fix it, that's all ... that hasn't changed from day one, and is unlikely to.' (GP principal, practice 21)

However, principals also acknowledged that the division of labour within the primary care team had altered in recent years. Practice nurses were widely seen as responsible for chronic disease management, with most GP principals stating that in addition to their usual acute primary care work, they now focused increasingly on two particular types of patients. Some GP principals described an increasing workload of patients who had complex problems that required an ability to handle uncertainty. Other principals spent more time seeing patients from their own practice and other local practices who had particular clinical conditions that were proving difficult to manage and might, a decade ago, have necessitated a referral to the local hospital clinic for a secondary care specialist opinion. These roles were not mutually exclusive and were generally seen as a positive addition to traditional medical work:

'I get the messy things and I rather like mess. Part of the philosophy is we try to allow chaos to tumble in the door and that we systematise it and we organise it and we then handle it.' (GP principal, practice 55)

'I am a cardiac GPwSI [GP with special interest]. I have got a plan for cardiac failure, defibrillation and palpitation, and special care. Consultants, they're in their castle. The GP they think doesn't know anything. GPs know the patients and spend more time.' (GP principal, practice 32)

'I don't see much minor illness any more and most consultations are either psychosocial or quite long and complicated.' (GP principal, practice 44)

Salaried GPs are most likely to describe their work in terms of seeing patients with acute problems and also seeing a small but growing group of patients with chronic illness whose care they share with the practice nurse. Much of the description of salaried GPs' working lives focused on negatives: of not doing visits, no involvement in the specific areas of chronic disease management, no specialist clinical 
interest, and little control over the type of work they undertook in the practice:

'Most of the time I see new problems ... they are coming in with new problems, but I do see chronic follow-up problems when their regular GP is not there.' (salaried GP, practice 49)

'We just have to get them all in and have their blood pressure checks and send them all off again. Yeah they all just have to whiz in and whiz out.' (salaried GP, practice 58)

\section{The creation of new practice hierarchies}

An interesting dichotomy emerged in terms of doctors' views about salaried and profit-sharing status. Most principals acknowledged the clinical work undertaken by salaried GPs, but some felt that salaried GPs were less committed to primary care, often ignored elements of the consultation (such as opportunistic recording of pay for performance measures), and were less flexible (working to rule on occasions). They emphasised their own long-term commitment to their patients and the community in contrast to the way they viewed salaried GPs. Their professional identity as GP principals was almost always linked to statements of treating people with problems, rather than medical problems that people have, and of living life in parallel with their patients, growing older with them, and of witnessing lives in the round:

'You have continuity, sort of, looking after your friends ... treating a group of your friends, playing a role in the same group of people's lives - the same group you see at Tescos when you are buying your shopping, as you do when you are in here, so it's part of the community.' (GP principal, practice 41)

I know cos we have excellent salaried people here on the payroll at the surgery. But I don't know, I just somehow think that if you don't have the, the entire responsibility then how can you make sure that you're always driving it forward, doing everything that you should? Cos it is a different philosophy if you sign up to a job that you want to go home to at 5.30 or 6.' (GP principal, practice 2)

While two of the seven salaried GPs described and welcomed their lower levels of responsibility, the others were keen to take on new roles including partnership, and contribute more fully to practice life. These five salaried GPs described feeling frustrated by limited responsibility both personally and on behalf of the cohort of younger doctors in a similar position. Most also expressed worries about their immediate job security and the prospect of having to move from practice to practice frequently to find work:

'I didn't particularly want a salaried job. When I moved up there wasn't a partnership available. I'm in a salaried position and obviously as you know it's meant to be that you just do your commitments and then sort of go. I, I would prefer, cos l'm young in my career, I'd prefer to be more involved with the practice side of it. I mean I could get involved as a salaried partner but I suppose there's no incentive because I wouldn't get paid any more or anything, so I sort of think, "What's the point?" ... I suppose when it comes to making a decision ultimately, it's the partners' decision not me and there's some meetings that I am not allowed to go to and I suppose that makes you feel a little bit ... so there's that extra level of commitment that, that I don't have really and I suppose in a way that's why I don't get paid as much but I would be willing to work hard.' (salaried GP, practice 4)

'I don't think you are going to have a family doctor who sees people from cradle to grave anymore. I think it will be a transient group of young salaried who don't only see themselves as GPs and will just move around every once in a while.' (salaried GP, practice 41)

Both groups of doctors noted the two-tier system that had developed in some practices in terms of the balance of money, power, and information, with salaried GPs, for example, excluded from certain meetings, discussions of new developments, and the financial side of practice life. Salaried GPs were likely to view this as income protectionism on the part of principals. In contrast, principals presented this approach as a necessary and flexible response to the changing workload and environment of primary care:

'We've got some excellent salaried doctors, but there is a distinct difference in the culture and how our practice is now made up. There are two tiers of medical practitioner and it has changed the dynamics and they do work slightly differently ... partners tend to just finish when the job is done and have lots of other responsibilities, the salaried doctors escape a lot of that, rightly so, and are a bit more rigid with how many patients they see and their commitment and flexibility is generally less so. So it's a new layer that we're still, I think, wondering how that will look in the future 
because we are, I suppose we're out of, including training grades, out of about 10, 11 doctors who pass through the building there's only six of us partners now. So the balance is altering and I'm not sure what we would do if a partner retired now, I think we probably would still look to replace with a salaried doctor until you got to a critical mass of partners where you felt you needed another partner to share out, you know, the other tasks. So I think that's caught us out a little bit, it seemed very easy to get on and collect salaried doctors to do some work. But I think then when you're making decisions and how the practice runs and the capacity isn't quite as obvious anymore because we'd all be in the same boat if it was a tough week, we'd all just do extra and stay on and get through it. One bit of the work force is a bit more fixed, and one bit is a little different so I think we're still getting our head round that a little bit. But again I think that's here to stay.' (GP principal, practice 4)

'I think the longer you are salaried, the more frustrating it becomes that you don't really have much say. I mean, I think, I ask myself, in 10 years time will I be happy to be a salaried GP? ... I think to its detriment ... they are not recruiting new partners, so I mean they are feathering their own nests essentially and I do think that it, the other aspect of it is I think they are abusing the younger generation of doctors.' (salaried GP, practice 41)

'It needs to be thought about quite carefully and it could very easily become a exploitative relationship, and I would, I think that would be detrimental ... I have heard of places where partnerships have kind of, condensed into one or two partners and anything from half a dozen upwards of salaried partners and that is a completely different concept to me, um, and one that I don't feel comfortable with at all really.' (GP principal, practice 49)

\section{Uncertain futures}

All but three of the doctors expressed uncertainties and fears about the future of primary care. Both principal and salaried doctors were concerned that, in the near future, primary care would be led by large private companies and/or all doctors might become salaried, and described how the sense of uncertainty made it difficult to plan for the future:

'We've had annual practice meetings since 1990 and at those meetings we plan ahead and the timeframe used to be, we would look at sort of this year and next year and 5 years, and then we dropped 5 years and then we looked at this year and next year, and now we don't look at next year, because we're sort of frightened to look ahead, because too much is unpredictable and uncertain. There seem to be so many options that are floating around, possibly bought out by Boots [pharmacy franchise] tomorrow or just being made redundant in a foul swathe, you know, the next day.' (GP principal, practice 49)

A move towards private provision of NHS primary care, managed by a range of private sector companies and provided by salaried doctors, was seen as threatening the highly prized independence of GPs, and of leading to greater fragmentation of services and poorer patient interpersonal continuity and care. The inherent tension of critiquing the motivations of private providers when GP principals were themselves running a small private business, employing salaried doctors, was rarely noted. However, where it was noted, larger private providers were described in contrast to GP principals as prioritising profit margins over patient care, with no commitment to the values and ethos of the NHS or to team working. GPs felt that they provided care and made profit as a consequence, whereas larger private providers made profit out of providing care:

'For most, most people, the sort of people who go into medicine, are going to feel a degree of commitment and want to do their best and be prepared to do a bit extra, whereas if you're employed by a private company and you know that the company is making profits which are being taken by people you never see and whose identities you don't know, people are much more likely to say, "Okay, it's, it's 5 past 5 now, and I finished at 5 o'clock, bye".' (GP principal, practice 30)

'I have this nightmare, you read these papers on who is going to run pharmacies or going to have GP surgeries, I said "My God, what's going to happen to the patients and us?". Maybe, if you have this private or alternate providers, is it going to [be] profit based? Are you going to have all this care or are they going to cherry-pick all these lovely easy bits, they are going to get all easy, nice bits to deal with and all the difficult bits come to us, and what do we do? And what about the patients? Are they going to get a better deal? Are they going to get continuity? Boots okay, they will be open maybe 9 to 5 and Saturday and Sundays it will be open, Tesco and those sorts of things, but what will happen? 
Who's got this problem, a difficult problem noone wants to deal with. Who's going to look after them? What's going to happen? And what about the GPs? I don't know what's going to happen to me. I feel extremely insecure.' (salaried GP, practice 49)

'Part of the magic is that I see the patient, and I've got the data in my computer, but I have the knowledge in my head ... so having continuity of information isn't the same as having relational continuity and I think that you get rid of relational continuity at your peril, because I think there are certain unmeasurables, and that is a strengthening of people's ability to cope. The way that we look at our first job is the relief of suffering, and our second job is to strengthen the patient's ability to cope ... so I think it is, it is the way that it's becoming, a Sainsbury's set of doctors, you know, they're good at selling beans, they sell beans better than we do, but in terms of healing people, in terms of getting people better?' (GP principal, practice 55)

Only one salaried GP, who expressed a desire for a portfolio career with time for non-medical pursuits, spoke positively about working in future for a private provider organisation, in terms of his own quality of life and working conditions.

\section{DISCUSSION}

\section{Summary of main findings}

While focused on English primary care, the intended and unintended consequences of changes to medical work and workforce and the potential impact of private providers are relevant to many other healthcare systems. ${ }^{13}$ Most GP principals described positive changes to their working life that required some of their previous acute and chronic care work to be undertaken by others in the practice. Many salaried GPs appeared to be resentful of their role and status as second-class clinicians within the increasingly hierarchical world of primary care. ${ }^{14}$ The financial disparity was particularly obvious, since between 2003 and 2006 salaried GPs had a 3\% pay rise and principals had one of $58 \% .{ }^{15}$ Practice nurses within the same practices echoed this resentment of the unequal distribution of new income. ${ }^{16}$ Almost all GPs felt uncertain about the future of primary care and were concerned about the potential threat of private providers delivering primary care to NHS patients through a largely salaried workforce. All except one salaried GP were committed to working within the current NHS structures if opportunities for partnerships were available. However, the potential tension created by GP principals' actions in employing more salaried GPs, and in some sense emulating the very private providers they professed to worry about, was rarely recognised.

\section{Strengths and limitations of the study}

Strengths of the study include the representative nature of the practices and GPs and the rigour with which data were collected and analysed by an experienced multidisciplinary research team.

The study has some limitations. In particular, it was only possible to interview seven of the eight salaried GPs employed by the practices, and no salaried GP in commercial organisations was interviewed. Green, however, has suggested that the generalisability of a qualitative study derives less from the representativeness of the sample than the concepts that may be relevant to other settings and groups. ${ }^{17}$ The present study also presents a data snapshot at one particular point in time. While GPs' views have been contextualised with nationally available data collected within the same time frame, there may also be inconsistencies between what the interviewees said and what they did in practice. It is also possible that the GPs wanted to present themselves in a particular light to the researchers.

\section{Comparison with existing literature}

Recent changes in primary care in England have been the focus of international interest and comment. Much of the evaluation has, however, been quantitative which may not enable an in-depth exploration of the consequences of change. ${ }^{18,19}$ Previous research on the redistribution of work in primary care has also tended to focus on the views of GP principals and practice nurses rather than salaried doctors. ${ }^{16,20,21}$

This paper provides a detailed account of the problems associated with new ways of working in primary care. GP principals described working differently during the day time, passing on routinised care to practice nurses and salaried GPs, and focusing on people with particular, often more timeconsuming, complex clinical or psychosocial issues. However, data suggest that practice nurses also dealt with significantly more self-reported complex visits in 2005 compared to 2003.22

This study also sheds new light on the views and working conditions of salaried GPs. Pinder has previously documented the negative stereotyping of non-principals that was evident in the present study in the context of salaried GPs. ${ }^{14}$ However, the 18 early-career salaried GPs interviewed by Jones and Green in 2005 reported high job satisfaction and success in achieving what they called 'nice work'. ${ }^{5}$ In their study, the notion of vocation was devalued as old fashioned, and a new professional ethic based on 
a stimulating but controlled workload within a democratic working environment was seen as key to the 'new general practice'. In contrast, 2 years further on, the still relatively early-career salaried GPs in this study were far less satisfied, and were aware of widening disparities in information, type of work, influence, and financial reward between doctors in the same practice.

\section{Implications for future research and clinical practice}

Healthcare professions are subject to changing boundaries and status in wider society. Changes have been dictated, on the international stage, for example, by the introduction of new technologies, workforce shortages or surpluses, consumer expectations, and new systems of purchasing, organising, and regulating the workforce. ${ }^{23}$ Nancarrow and Borthwick have suggested a useful taxonomy for understanding how and why medical workforce boundaries change, and describe intradisciplinary change through diversification and specialisation and interdisciplinary change through horizontal and vertical substitution. ${ }^{24}$ Larkin suggests that the development of specialisation may depend on the ability of the professional group to delegate certain aspects of their work to other providers. ${ }^{25}$ It involves the creation of subordinate subgroups within a profession, which undertake lower-status duties, freeing the professionals to pursue higherstatus autonomous roles. Within the context of this study, greater specialisation appears to be occurring in primary care, with GP principals actively 'specialising in generalism' or adopting new roles and identities, through vertical substitution, for example, as GPs with a special clinical interest. Salaried GPs, in contrast, appear to be adopting the left-over or discarded jobs, mopping up the less complex and perhaps less professionally satisfying or challenging patients, echoing Hughes' work on the division of labour based on 'dirty work'. ${ }^{26}$

Many of the salaried GPs in this study felt disenfranchised and disillusioned by their role and lack of influence in decision making and the type of work they performed in the practice. They were acutely aware of the practice-created hierarchy and of being on the bottom of a two-tier system. As Jones and Green have demonstrated, however, a sense of disillusionment is not an automatic part of salaried status. ${ }^{5}$ Instead, it may be a by-product of the recent well-publicised salary differential and move towards a less satisfying workload. In the US, salaried GPs in a large not-for profit group-model health maintenance organisation reported high levels of satisfaction with their careers, pay, and level of autonomy. ${ }^{27}$ However, importantly, they had opportunities to participate in decisions that affected their working life and had salaries and benefits comparable with those of physicians in the wider medical community. The Royal College of General Practitioners and General Practitioners Committee of the BMA have recently begun to address some of the issues around salaried GPs through a joint discussion paper on the current state and future shape of GP partnerships. ${ }^{28}$ They suggest that GPs could work together as teams rather than as salaried doctors or partners. Roles could be based on functions with overlap where required. However, the system is untested and remuneration within it unclear. In the current English context, it remains to be seen if GP principals will recognise the tensions and potential dangers of creating an increasingly disenfranchised salaried labour force, recreating smaller versions of the private provider organisations they suggest may spell the end of NHS primary care.

Further work is now required to explore how principals make the decision to replace a retiring partner with a salaried doctor or principal, and explore how cognisant they are of the effect that their decision may have on the future of primary care.

\section{Funding body}

This work was done at the National Primary Care Research and Development Centre, which receives funding from the Department of Health. The views expressed are those of the authors and not necessarily those of the Department of Health

\section{Ethics committee}

Ethical committee approval was provided by North West Research Ethics Committee

\section{Competing interests}

Helen Lester currently provides academic advice on evidence-based medicine to the national QOF negotiating teams

\section{Acknowledgements}

The authors wish to thank the GPs who agreed to be interviewed.

\section{Discuss this article}

Contribute and read comments about this article on the Discussion Forum: http://www.rcgp.org.uk/bjgp-discuss

\section{REFERENCES}

1. The NHS Information Centre - Workforce and Facilities. General and personal medical services. England. 1998-2008. Leeds: The Health and Social Care Information Centre, 2009

http://www.ic.nhs.uk/statistics-and-data-collections/workforce/nhsstaff-numbers/nhs-staff-1998--2008-general-practice (accessed 30 Sept 2009).

2. British Medical Association. Employment and contracts. http://www.bma.org.uk/employmentandcontracts/index.jsp (accessed 30 Sept 2009).

3. Ding A, Hann M, Sibbald B. Profile of English salaried GPs: labour mobility and practice performance. Br J Gen Pract 2008; 58(546): $20-25$.

4. Gosden J, Williams J, Petchey R, et al. Salaried contracts in UK general practice: a study of job satisfaction and stress. J Health Serv Res Policy 2002; 7(1): 26-33.

5. Jones L, Green J. Shifting discourses of professionalism: a case study of general practitioners in the United Kingdom. Sociol Health Illn 2006; 28(7): 927-950.

6. Department of Health. Alternative providers of medical services 
(APMS)

http://www.dh.gov.uk/en/Healthcare/Primarycare/Primarycarecontra cting/APMS/index.htm (accessed 30 Sept 2009).

7. Pollock A, Price D, Viebrock E, et al. The market in primary care. BMJ 2007; 335(7618): 475-477.

8. Salisbury C. The involvement of private companies in NHS general practice. BMJ 2008; 336(7641): 400-401.

9. Campbell SM, Roland MO, Middleton E, Reeves D. Improvements in the quality of clinical care in English general practice 1998-2003: longitudinal observational study. BMJ 2005; 331(7525): 1121-1125.

10. Roland MO, Campbell SM, Bailey N, et al. Financial incentives to improve the quality of primary care in the UK: predicting the consequences of change. Prim Care Res Dev 2006; 7: 18-26.

11. Strauss A, Corbin J. Basics of qualitative research: grounded theory procedures and techniques. London: Sage, 1990.

12. Silverman D. Interpreting qualitative data. Methods for analysing talk, text and interaction. London: Sage, 1997.

13. McKinlay J, Marceau L. When there is no doctor: reasons for the disappearance of primary care physicians in the US during the early 21 st century. Soc Sci Med 2008; 67(10): 1481-1491.

14. Pinder R. On the margins: belonging in general practice for women part timers and non-principals. Fam Pract 1998; 15(4): 363-368.

15. Kmietowicz Z. Contract for GPs in England failed to live up to expectations. BMJ 2008; 337: a2025.

16. Campbell S, McDonald R, Lester HE. The experience of pay for performance in English family practice: a qualitative study. Ann Fam Med 2008; 6(3): 228-234.

17. Green J. Generalisability and validity in qualitative research. $B M J$ 1999; 319(7207): 421.
18. Campbell SM, Reeves D, Kontopantelis E, et al. Quality of primary care in England with the introduction of pay for performance. $N$ Engl J Med 2007; 357(2): 181-190.

19. Doran T, Fullwood C, Gravelle H, et al. Pay-for-performance programs in family practices in the United Kingdom. N Engl J Med 2006; 355(17): 375-384

20. Checkland K, Harrison S, McDonald R, et al. Biomedicine, holism and general medical practice: responses to the 2004 general practitioner contract. Sociol Health Illn 2008; 30(5): 788-803.

21. Charles-Jones H, Latimer J, May C. Transforming general practice: the redistribution of medical work in primary care. Sociol Health Illn 2003; 25(1): 71-92.

22. Gemmell I, Campbell SM, Hann M, Sibbald B. Assessing workload in English general practice before and after the introduction of pay-forperformance. J Adv Nurs 2009; 65(3): 509-515.

23. Cooper RA, Henderson T, Dietrich CL. Roles of nonphysician clinicians as autonomous providers of patient care. JAMA 1998; 280(9): 795-802.

24. Nancarrow S, Borthwick A. Dynamic professional boundaries in the health care workforce. Sociol Health Illn 2005; 27(7): 897-919.

25. Larkin G. Occupational monopoly and modern medicine. London: Tavistock, 1983.

26. Hughes EC. Men and their work. Toronto: Free Press of Glencoe, 1958.

27. Freeborn D, Hooker R, Pope C. Satisfaction and well-being of primary care providers in managed care. Eval Health Prof 2002 25(2): 239-254.

28. Gerada C, Weeks V. Changing partnerships. London: Royal College of General Practitioners, 2009. 